\title{
RUANG INTERAKTIF DI MERUYA UTARA
}

\author{
Ursula Andrea ${ }^{1)}$ \\ 1) Program Studi S1 Arsitektur, Fakultas Teknik, Universitas Tarumanagara, uaocto@gmail.com
}

\begin{abstract}
Abstrak
Third place adalah tempat netral, dan sederhana (unpretentious). Tempat ini haruslah playful atau menyenangkan bagi siapapun, sehingga ketika meninggalkan third place, orang keluar dengan bahagia. Tempat ini tidak memiliki aturan yang ada di rumah maupun tempat kerja. Third place juga merupakan tempat masyarakat berkumpul, dan memiliki status yang sama. Selain itu dalam proyek ini third place hadir sebagai bentuk dari open architecture yang bersahabat dengan lingkungannya dan membuat kota menjadi lebih baik. Aktifitas utama dari proyek ini adalah interaksi dengan program yang ditawarkan, aktifitas itu sendiri maupun dengan sesama pengunjung. Fokus third place ditunjukan pada dampak dari "The Solidarity Economy" atau ekonomi solidaritas yang menurut Ethan Miller dari Grassroots Economic Organizing Collective di Australia, The "solidarity economy", adalah sebuah undangan untuk menjangkau lingkupan yang luas mengenai cara kerja ekonomi yang berlandaskan berbagi. Sistem ini memudahkan masyarakat untuk dapat mengakses fasilitas tanpa memiliki sesuatu yang akan menciptakan interaksi antara pengunjung dengan pengunjung. Hal ini terjadi karena proyek ini dirancang untuk membentuk aktifitas komunal. Adapun aktifitas komunal yang terjadi adalah aktifitas yang bersifat playful. Seperti, ruang misbar, café boardgame dan juga ruang olahraga yang bersifat tidak kompetitif. Seperti sebagaimana kriteria yang terdapat pada teori third place yang memiliki kriteria playful. Ruangan-ruangan yang terbentuk dirancang dan direncanakan agar setiap pengunjung bisa berinteraksi dengan pengunjung lain maupun dengan program yang sudah ada.
\end{abstract}

Kata kunci: interaktif; playful; third place

\begin{abstract}
Third place is a neutral place, and simple (unpretentious). This place must be playful or fun for anyone, so that when leaving the third place, people come out happily. This place has no rules at home or work. Third place is also a place where people gather, and have the same status. Also in this project the third place comes as a form of open architecture that is friendly to the environment and makes the city better. The main activity of this project is the interaction with the programs offered, the activity itself and with fellow visitors. The focus of the third place is shown on the impact of "The Solidarity Economy" or according to Ethan Miller of the Grassroots Economic Organizing Collective in Australia, The "solidarity economy", is an invitation to reach a broad scope of the workings of an economy based on sharing. This system makes it easy for people to be able to access facilities without having something that will create interaction between visitors and visitors. This happened because the project was designed to form communal activities. The communal activities that occur are playful activities. Like, misbar space, café boardgame and also sports space that is not competitive. Like the criteria contained in the third place theory which has playful criteria. The rooms that are formed are designed and planned so that each visitor can interact with other visitors and with existing programs.
\end{abstract}

Keywords: interactive; playful; third place 


\section{PENDAHULUAN}

\section{Latar Belakang Proyek}

Jakarta adalah sebuah ibukota negara dengan berbagai potensi dan masalahnya. Jakarta memliki luas $661.5 \mathrm{~km}^{2}$ dan 10.348 .570 jiwa berdasarkan data statistik tahun 2019 . Kepadatan tertinggi berada di Jakarta Pusat dengan rasio kepadatan $23.669 .86 \mathrm{jiwa} / \mathrm{km}^{2}$ dan terpadat ke 2 merupakan Jakarta Barat dengan 17.965.67 jiwa/km².

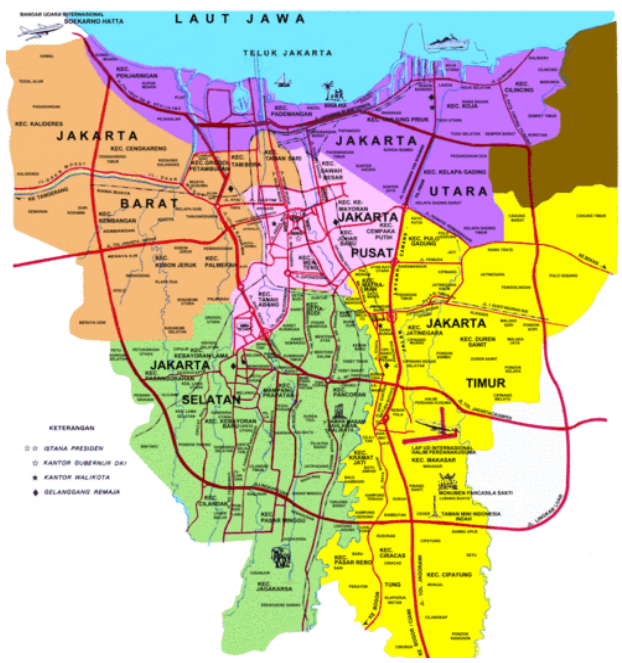

Gambar 1. Peta Kota DKI Jakarta

Sumber: Wikipedia, 2019

Tapak berada di area yang memiliki perumahan, tempat ibadah, sekolah, perkantoran serta beberapa apartemen. Pada pagi hari kawasan ini dilalui oleh orang-orang yang hendak berangkat kerja atau bersekolah, sedangkan pada siang hari banyak pegawai kantor yang mencari makan di luar kantor dan makan di waktu istirahatnya dan anak sekolah yang pulang dari sekolah. Selain itu pada sore hari tapak kembali padat dengan aktifitas pulang kantor. Selain itu juga ditemukan beberapa tempat makan yang mulai buka pada malam hari.

Pada akhir pekan, kawasan proyek tetap ramai dilalui oleh berbagai kendaraan walaupun tidak ada aktifitas kantor. Akan tetapi pada tepat di sebelah tapak terdapat sebuah gereja yang beaktifitas pada hari Rabu, Sabtu dan Minggu yang menjadikan opportunity bagi proyek untuk tetap beroperasi pada hari libur sekalipun.

Berdasarkan Oldenburg (1989), Third place merupakan tempat yang menjadi perantara antara rumah dan tempat kerja. Tapak berada di antara kedua tempat tersebut dengan first place yang merupakan daerah perkantoran, sekolah dan pertokoan, dan first place berupa pemukiman 2 -3 lantai, apartemen dan beberapa area perumahan lainnya.

\section{Pertanyaan Penelitian}

Bagaimana arsitektur, bisa mewadahi aktifitas third place pada masyarakat yang memiliki berbagai latar belakang dan menjadikannya sebagai tempat yang netral?

\section{Batasan Masalah}

Masalah dibatasi pada solusi, tanggapan, penyelesaian terhadap kebutuhan third place di antara first dan second place di Jalan Meruya Illir.

\section{Tujuan Penelitian/Desain}

Tujuan atas penelitian dan perancangan ini adalah untuk merancang ruang yang dapat mewadahi kegiatan third place bagi dan untuk masyarakat yang berada dan atau tinggal di sekitar tapak. 


\section{KAJIAN LITERATUR}

\section{Berdasarkan Oldenburg (1989), terdapat 8 kriteria Third place :}

Ruang neutral yang jauh dari first place (rumah) dan second place (tempat kerja) dimana kegiatan utama ialah berinteraksi bertukar pikiran dan cenderung makanan ditawarkan diantara kegitan tersebut.

8 Karakteristik yang menjelaskan apa itu third place menurut Oldenburg (1989):

- Neutral ground: tidak terikat dari segi politik, ekonomi, aspek lainnya, penggunjung tidak memiliki obligasi dan bebas untuk mendatangi tempat tersebut.

- Leveler: tidak memandang status, third place menerima semua kalangan tanpa syarat partisipasi.

- Dialogical: komunikasi sebagai kegiatan utama yang bersifat ramah dan menyenangkan.

- Accessibility and accommodation: selalu terbuka saat diperlukan dan memenuhi semua kebutuhan penggunjung.

- The regulars: memiliki pengunjung tetap yang mendasari karakteristik tempat namun juga menyambut pengunjung baru untuk merasa nyaman.

- A low profile: tanpa pemborosan atau hal yang berlebihan, kesederhanaan yang dapat menerima semua pengunjung dari berbagai latar belakang pengalaman hidup, memiliki kesan rumah bagi pengunjung.

- The mood is playful: menciptakan suasana yang ringan jauh dari adanya konflik atau pun pertentangan yang tidak menyenangkan.

- A home away from home: menyediakan kehangatan seakan-akan merasa bagian dari komunitas, seperti rumah sendiri, di mana pengunjuk mendapati energi positif dari lingkungannya.

Third place harus mengandung ke 8 unsur tersebut untuk mencapai sebuah tempat yang netral dan menyenangkan untuk pengunjungnya.

\section{The Solidarity Economy}

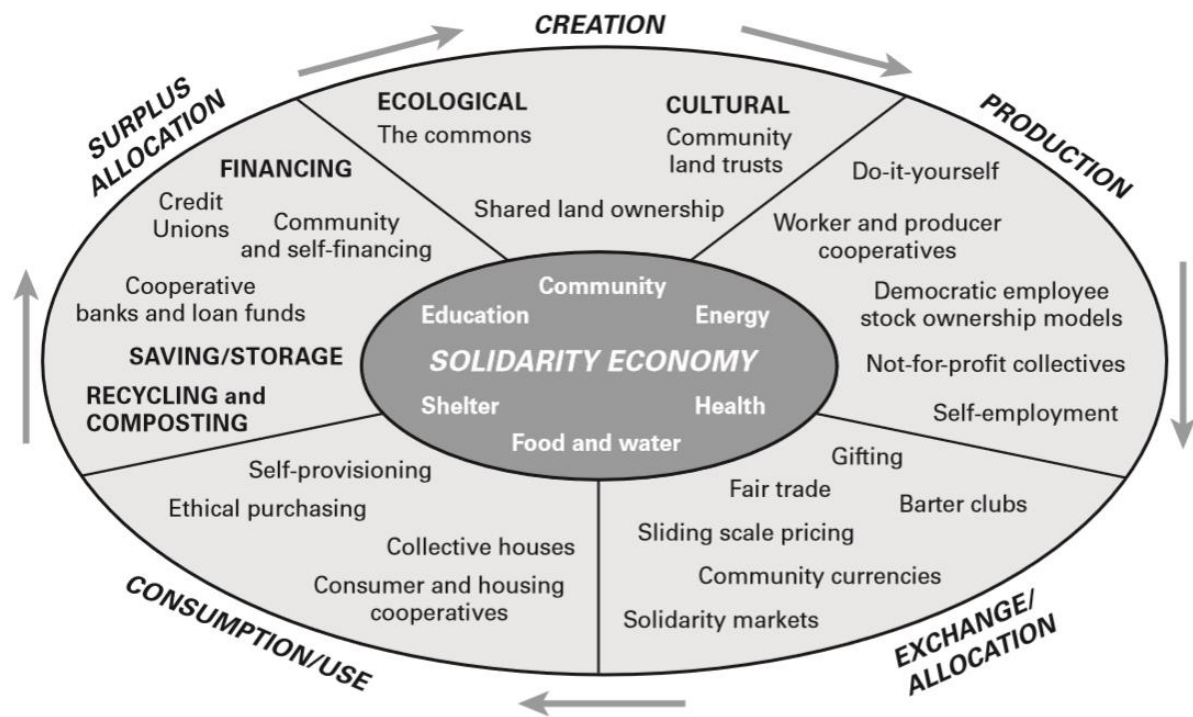

Gambar 2. The Solidarity Economy

Sumber: McLaren, 2019

Tantangan dan peluang dari sharing city adalah suatu kesatuan, sekitar $53 \%$ penduduk bumi tinggal di kota. Hal ini akan meningkat menjadi $64.1 \%$ pada bagian selatan bumi dan $85.9 \%$ di bumi bagian utara pada tahun 2050 . Semakin banyak penduduk berarti semakin banyak masalah 
dan juga semakin banyak potensi. Semakin banyak penduduk berarti semakin banyak juga mulut yang harus diberi makan dan tempat tinggal. Di sisi lain hal tersebut meningkatkan pertumbuhan ekonomi. "Truly smart cities must also be sharing cities.", pernyataan ini mendasari adanya program shared kitchen dan perpustakaan. Di mana berbagi adalah berusaha ditanamkan pada pengguna maupun pengelola. Dengan terdistribusinya pengetahuan dan makanan, diharapkan gizi dan kualitas masyarakatnya bisa meningkat.

Dalam buku ini juga dibahas bahwa pekerjaan yang merata sebanyak 30 jam per minggu untuk semua pekerja akan lebih baik. Hal ini akan menyelesaikan banyak masalah, seperti : overwork, pengangguran, overconsumption, emisi gas yang tinggi, rendahnya kualitas hidup, ketidakmerataan dan kurangnya waktu untuk hidup yang berkesinambungan, dan menikmati hidup. Pada dasarnya hal ini berpengaruh kepada kualitas hidup masyarakat kota. Apabila kualitas hidup semakin buruk maka kualitas kotanya juga akan menjadi buruk.

Taman merupakan tempat yang penting dalam kehidupan bersama di lingkungan yang heterogen dan di tengah kota. Menciptakan tempat dapat dilakukan dengan membagi hasil panen, bibit, pengetahuan, dan resep adalah cara paling efektif dalam menjembatani perbedaan budaya.

The "solidarity economy," berdasarkan Ethan Miller dari Grassroots Economic Organizing Collective di Australia (2010), adalah sebuah undangan. Menjangkau lingkupan yang luas mengenai cara kerja ekonomi yang berlandaskan berbagi. Dengan berbagai entitas dan pendekatan termasuk lingkaran pinjaman, pendanaan masyarakat, penganggaran partisipatif, mata uang masyarakat, serikat kredit, koperasi, kerja sama, kebun masyarakat, proyek sumber terbuka, kolektif seni, perwalian tanah masyarakat, perumahan bersama, ruang publik terbuka, kolektif layanan kesehatan, bank waktu, media milik masyarakat, perpustakaan, pasar barter, pembagian makanan gratis, dan organisasi keadilan sosial dan lingkungan yang mendukung pendekatan semacam itu, termasuk serikat pekerja, organisasi nirlaba, dan bisnis progresif.

Organisasi ekonomi solidaritas tidak hanya berbagi organisasi, tetapi dalam hampir setiap kasus - sesuai dengan sifat kolektif dari proyek solidaritas - ada beberapa bentuk kegiatan berbagi.

\section{METODE}

Metode pengumpulan data menggunakan tinjau lokasi, mengamati kegiatan di sekitar tapak, studi kasus, survey lapangan, buku, dan data dari internet. Tahap desain dimulai dari isu, literatur, kuesioner terhadap milenial terutama, studi kasus proyek serupa baik luar negri dan dalam negri, program, survey lokasi, analisa lokasi baik makro hingga mikro, gubahan massa dipadupadankan dengan analisa lokasi, metode program memanfaatkan teori dari Ray Oldenburg dan Sharing Economy, sistem bangunan dan detail.

Analisa lokasi dilakukan dengan pemetaan 2 dimensi dari makro, meso, hingga mikro. Dalam mendesain gubahan massa, pendekatan yang dilakukan adalah pendekatan hasil program, pendekatan analisa tapak, dan pendekatan terhadap teori Ray Oldenburg \& Sharing Cities.

Metode yang digunakan sebagai panduan dalam proyek ini adalah:

1. Tipologi digunakan sebagai tahap awal penelitian terhadap tapak. Pada tahap ini bangunan disekitar dikelompokan dalam berbagai macam jenis untuk mengetahui tipe third place yang mendominasi daerah tersebut.

2. Trans-programming digunakan sebagai acuan dalam memasukan hubungan antara space dan event.

\section{DISKUSI DAN HASIL}

\section{Analisa Tapak}

Tapak berada di Jl. Meruya Illir Raya, Kecamatan Meruya Utara, Jakarta Barat, DKI Jakarta. Tepatnya berada di zona perumahan, pelayanan umum sosial, dan perkantoran. Berikut tabel zonasi RDTR Tapak: 

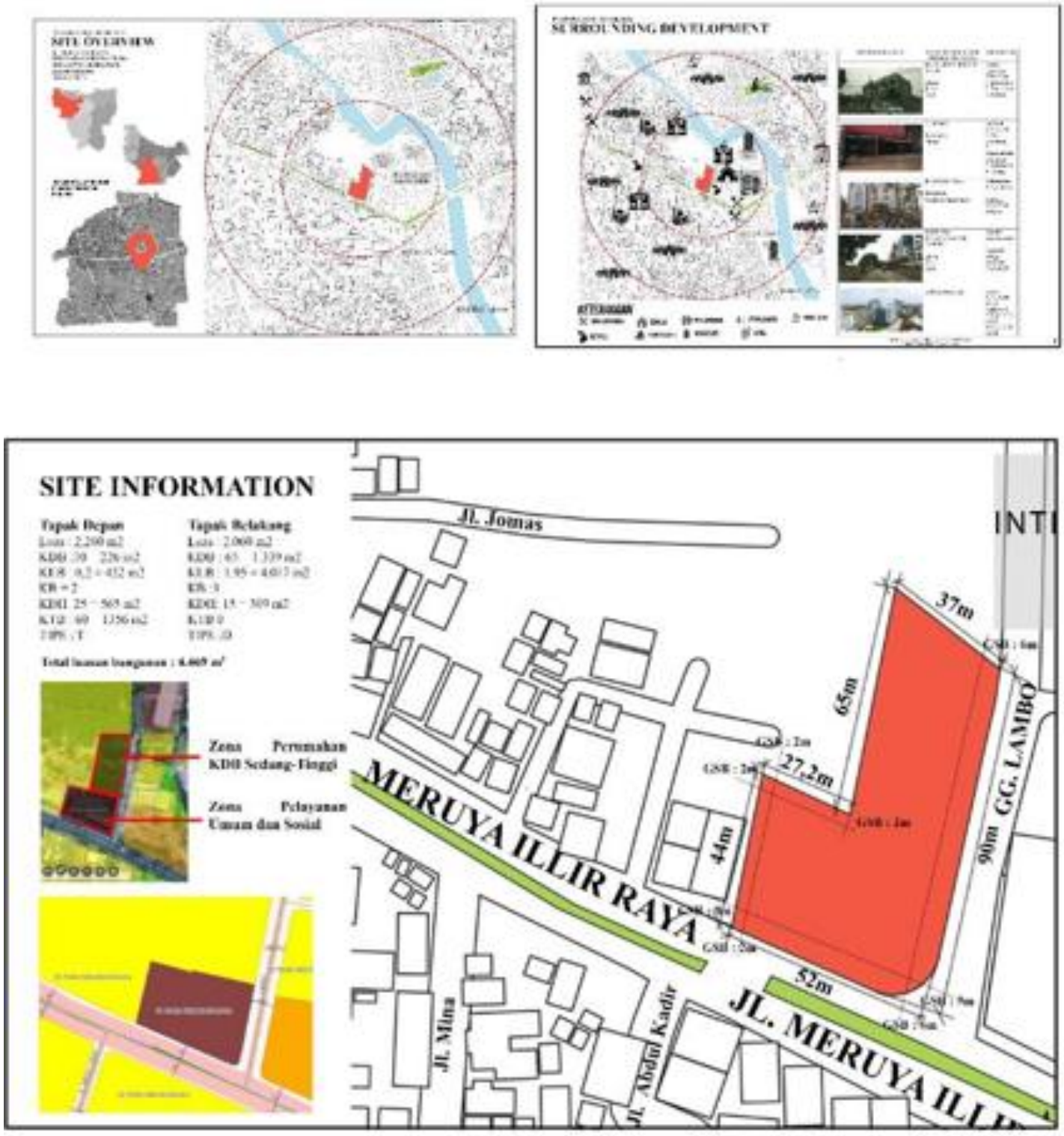

Gambar 3. Analisa Makro, Meso, Mikro

Sumber: Penulis, 2019

Pada tapak terdapat 2 zona penggunaan lahan. Dimana pada perda DKI Jakarta No. 1 Tahun 2014 Pasal 614 ayat 1 c. menyatakan bahwa lahan perencanaan satu kepemilikan yang memiliki lebih dari satu zona dapat dihitung secara proporsional. Jalan Meruya Ilir adalah jalan kolektor yang menghubungkan Jalan Pesanggrahan dan Jalan Panjang. Pada jalan ini terdapat pertokoan dan kompleks rukan bernama Business Park Kebon Jeruk dan belmont. Tapak berada di antara pemukiman warga dan kompleks rukan Business Park Kebon Jeruk yang di dalamnya terdapat rukan, apartemen dan sebuah gereja. 
Tabel 1. Zonasi RDTR Tapak

$\begin{array}{ll}\text { TAPAK DEPAN } & \text { TAPAK BELAKANG } \\ \text { KDB }: 10 & \text { KDB }: 65 \\ \text { KLB }: 0.2 & \text { KLB }: 1.95 \\ \text { KB }: 2 & \text { KB }: 3 \\ \text { KDH }: 25 & \text { KDH }: 15 \\ \text { KTB }: 60 & \text { KTB }: 0 \\ \text { TIPE }: \text { T } & \text { TIPE }: D\end{array}$

\section{LUAS TAPAK}

\begin{tabular}{|c|c|c|c|}
\hline & tapak depan & tapak belakang & total \\
\hline luas & 2481.432 & 2071 & 4552.432 \\
\hline kdb & 248.1432 & 1346.15 & 1594.2932 \\
\hline $\mathrm{klb}$ & 496.2864 & 4038.45 & 4534.7364 \\
\hline $\mathrm{kb}$ & 2 & 3 & \\
\hline kdh & 620.358 & 310.65 & 931.008 \\
\hline ktb & 1488.8592 & 0 & 1488.8592 \\
\hline tipe & $\mathrm{t}$ & d & \\
\hline
\end{tabular}

Sumber: Perda DKI Jakarta No.1 Tahun 2014

Proses gubahan massa memaksimalkan entrance masuk dan kegiatan di dalam tapak menjadikan proyek memiliki orientasi ke dalam dan menuju ke program utama yaitu interaksi sosial melaui misbar dan area makan yang digabung bersama.

\section{Program}

Berdasarkan hasil survey lokasi lebih dari 55\% third place dihitung dari radius 500 meter sekitar kawasan merupakan area komersial yang menyediakan makanan. Dilanjutkan dengan tempat olahraga, seperti GOR, Gelanggang Remaja, dan Sportclub dan ada juga tempat pemancingan. Adapun proyek yang dirancang merupakan sebuah public space yang tentunya harus mengundang orang banyak untuk datang ke tapak. Berdasarkan Buku Pattern Language ada 8 aktifitas yang dapat menarik orang untuk datang ke tapak kita. Ke 8 aktifitas tersebut adalah:

1. Pertokoan

2. Stands

3. Tempat duduk

4. Displays

5. Rails

6. Courts

7. Taman

8. New racks

Berdasarkan teori Sharing Economy yang juga mendukung third place sebagai tempat yang setara. Maka program yang terjadi adalah tempat makan dengan meja memanjang, bersifat terbuka, bisa sambil nonton bersama dan aktifitas bermain seperti boargame dan sasana.

Dengan Sharing economy kita tidak perlu memiliki barang kita hanya perlu bisa mengaksesnya. Adapun adanya tempat makan bersama bukan berarti kita harus memiliki ruang makan tersebut. Kita bisa menikmatinya dengan membeli makanan. Begitu pula dengan sasana. Tidak perlu memiliki alat fitness. Pengunjung bisa menggunakan dengan menjadi anggota. Hal ini juga sekaligus mendatangkan regulars karena adanya keanggotaan pada gym. Selain itu program ini juga tercipta karena Jakarta Barat merupakan kota dengan kasus obesitas tertinggi se DKI Jakarta. 


\section{Konsep dan Bentuk Rancangan}

Tapak proyek yang berbentuk $L$ memiliki tantangan tersendiri dalam merancang. Maka dari itu adanya buku sumber konsep sangat membantu dalam menentukan bentuk dasar pada tapak dengan memiliki sumbu ruangan yang jelas. Dengan sirkulasi ditengah dengan kegiatan di sepanjang jalannya.
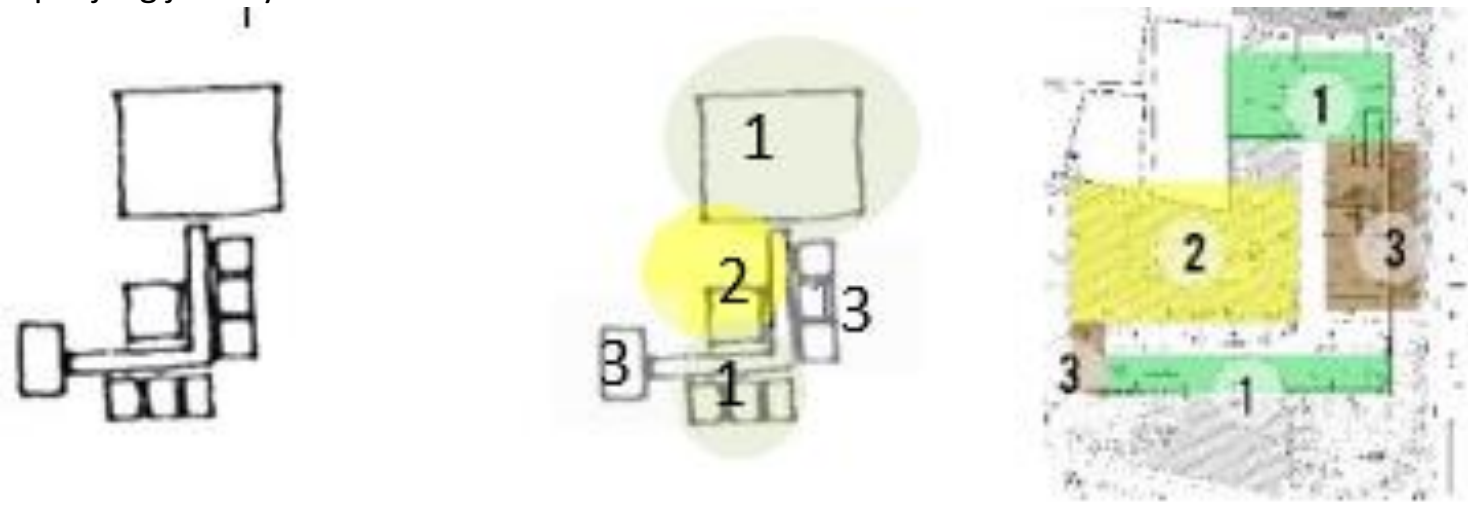

Gambar 4. Konsep Gubahan Massa

Sumber : White, 1985 \& Penulis, 2019

Bisa kita lihat pada bagian nomor 1 dijadikan bukaan/entrance. Karena letaknya dekat dengan pertemuan pejalan kaki dan mobil, berdasarkan buku pattern language ruangan ini cocok untuk dijadikan food stands. Pada bagian nomor 2 merupakan pusat aktifitas dimana pengunjung bisa makan sambil menonton misbar. Adapun hal ini di rancang untuk menciptakan atmosfer yang ringan dan menyenangkan seperti yang seharusnya terjadi pada third place.

Pada bagian drop off mobil di buat pembatas visual pohon dengan area parkir hal ini dilandasi dengan buku Pattern Language di mana parkir haruslah tidak bisa dilihat secara langsung. Baik itu dibatasi dengan natural wall, building, connected houses, earth beams, ataupun pertokoan.

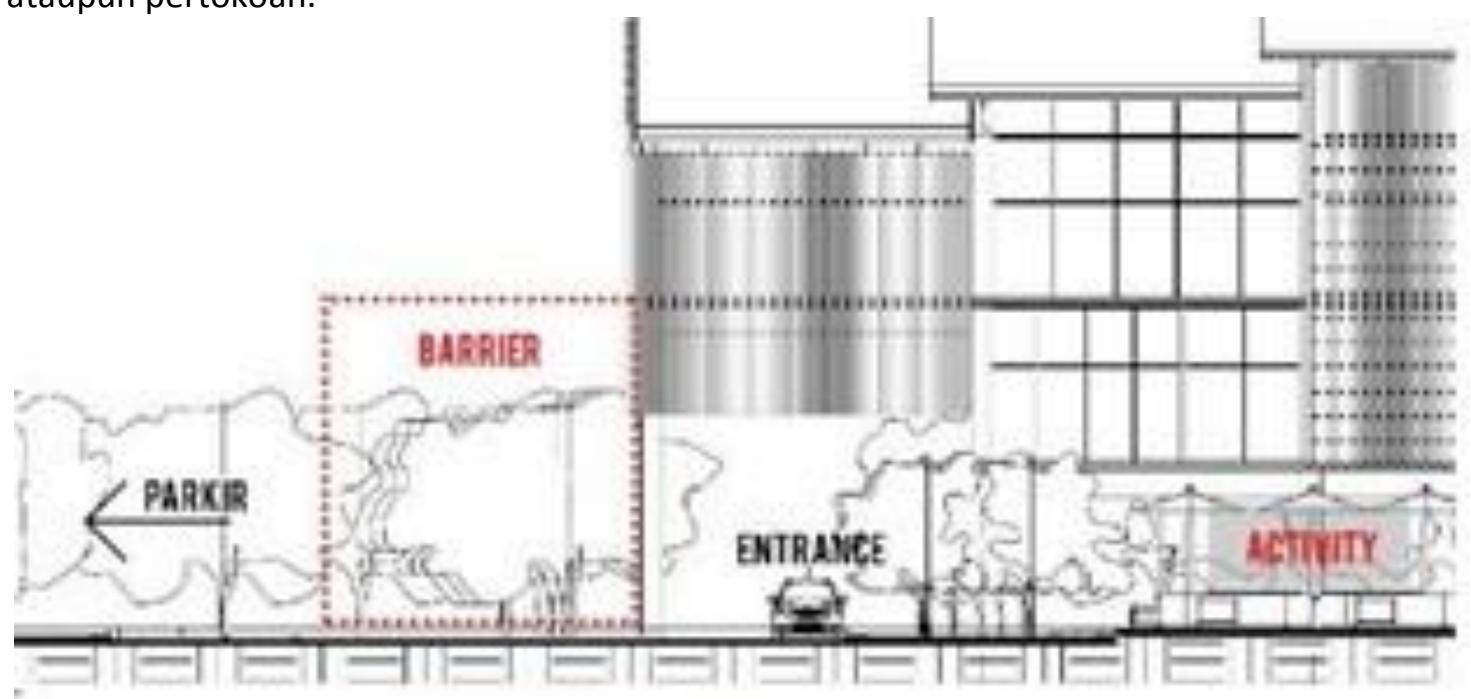

Gambar 5. Potongan D-D

Sumber: Penulis, 2019 


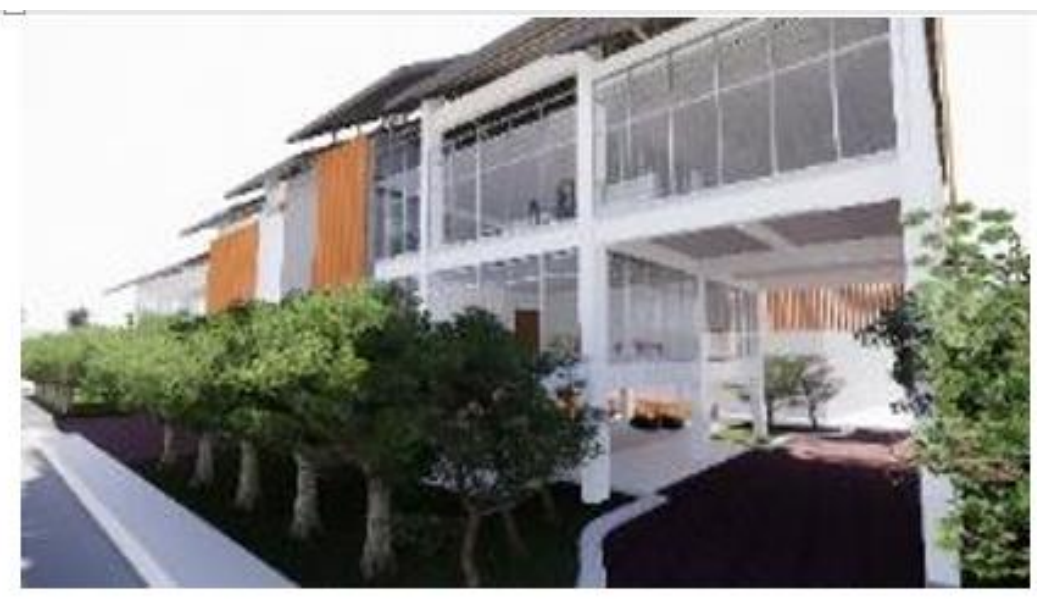

Gambar 6 : perpsektif entrance kendaraan Sumber : dokumentasi pribadi 2019

Gambar 7: pengendalian cahaya pada bangunan Sumber : Buku Sumber Konsep, Edward T. White, 1985

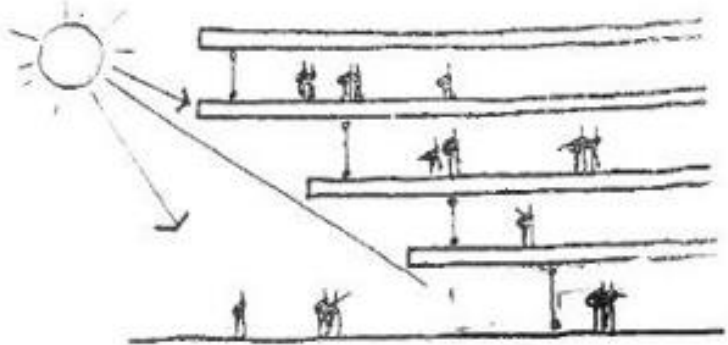

Selain itu untuk membuat cahaya matahari tidak terkena langsung ke bangunan maka di atas drop off dibuat ruangan yang fungsional. Hal ini disebabkan karena terbatasnya KDB dan luasan lahan yang bisa digunakan sebagai tempat parkir.

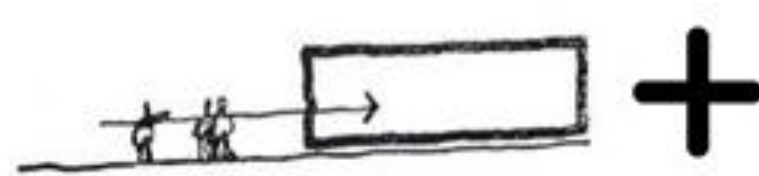

LANGSUNE MASUK

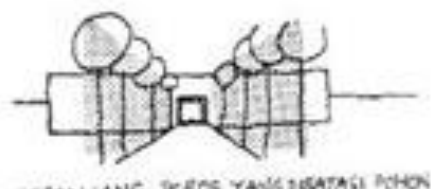

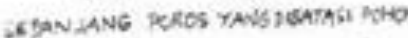

Gambar 8. cara masuk ke bangunan

Sumber : Buku Sumber Kosep, Edward T. White 1985

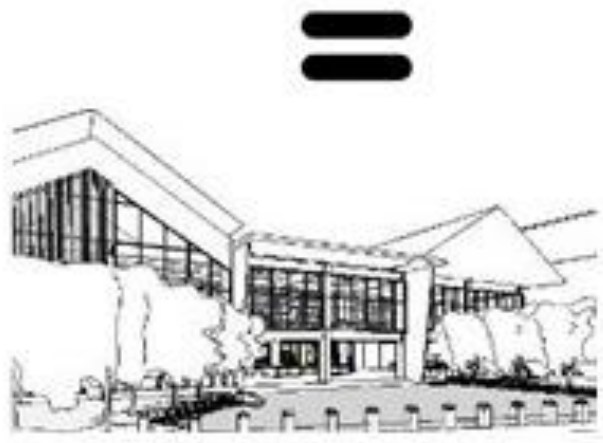

Gambar 9. perpsektif entrance pejalan kaki

Sumber : dokumentasi pribadi 2019 
Untuk entrance utama proyek dibuat seterbuka mungkin dengan diiringi pohon yang mengarah pada pintu masuk. Hal ini dilakukan agar pengunjung terutama pejalan kaki bisa langsung tertuju pada pintu utama. Selain itu adanya bollard juga digunakan untuk menyaring pengunjung agar tidak ada kendaraan yang bisa sembarangan masuk. Adapun hal ini dilakukan untuk mengantisipasi kemacetan yang disebabkan oleh keluar masuknya kendaraan. Hal ini diantisipasi karena adanya putaran pada bagian depan tapak.

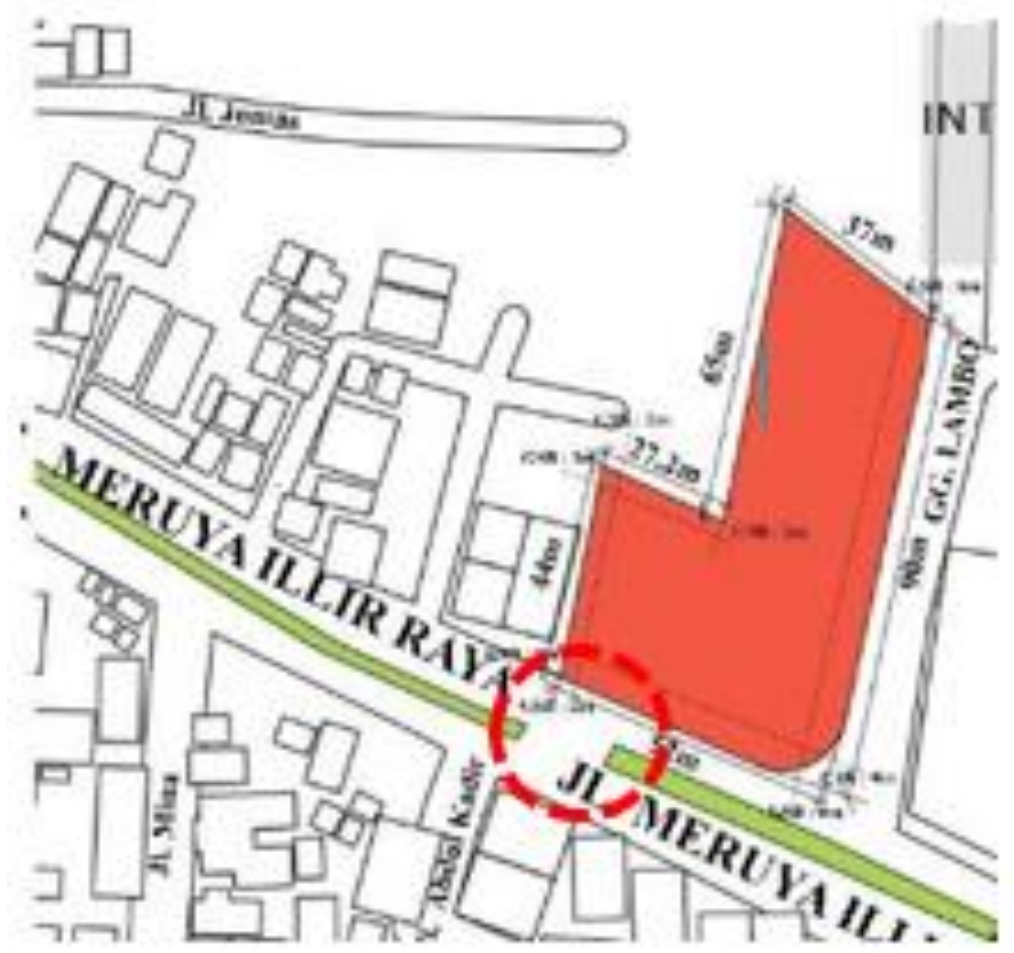

Gambar 10. Putaran di depan Tapak

Sumber: Penulis, 2019

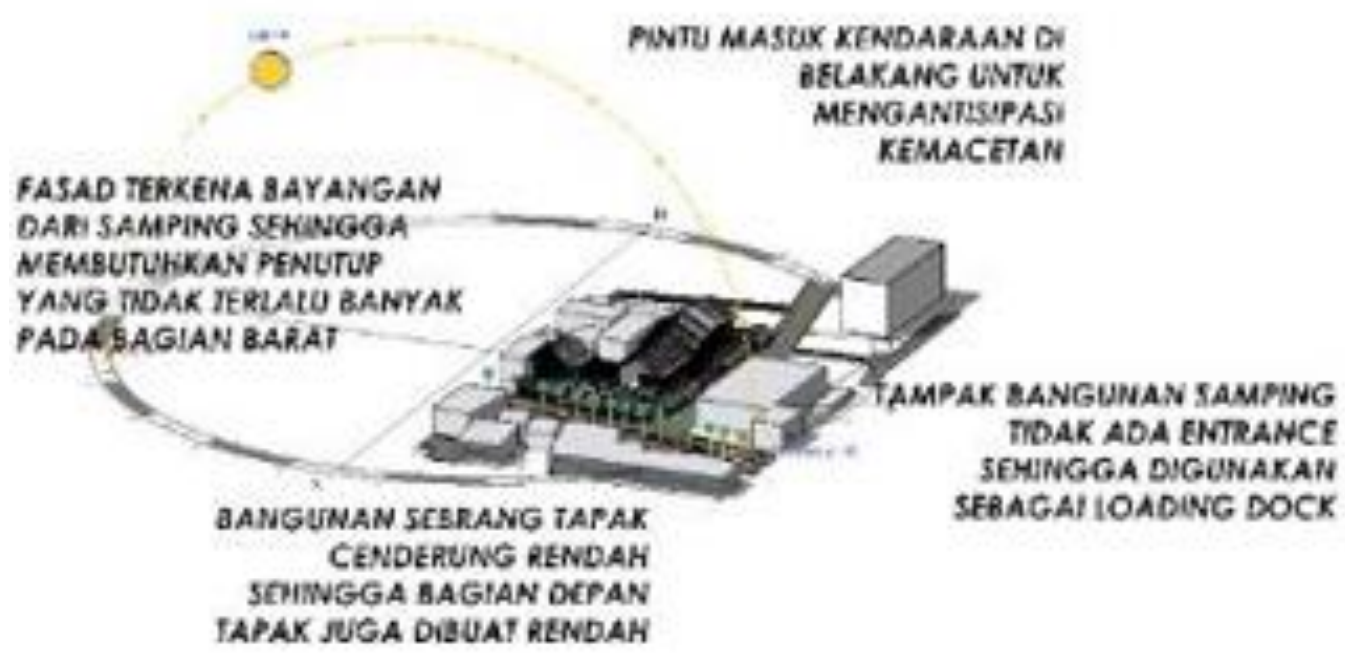

Gambar 11. Analisis Tapak

Sumber: Penulis, 2019 


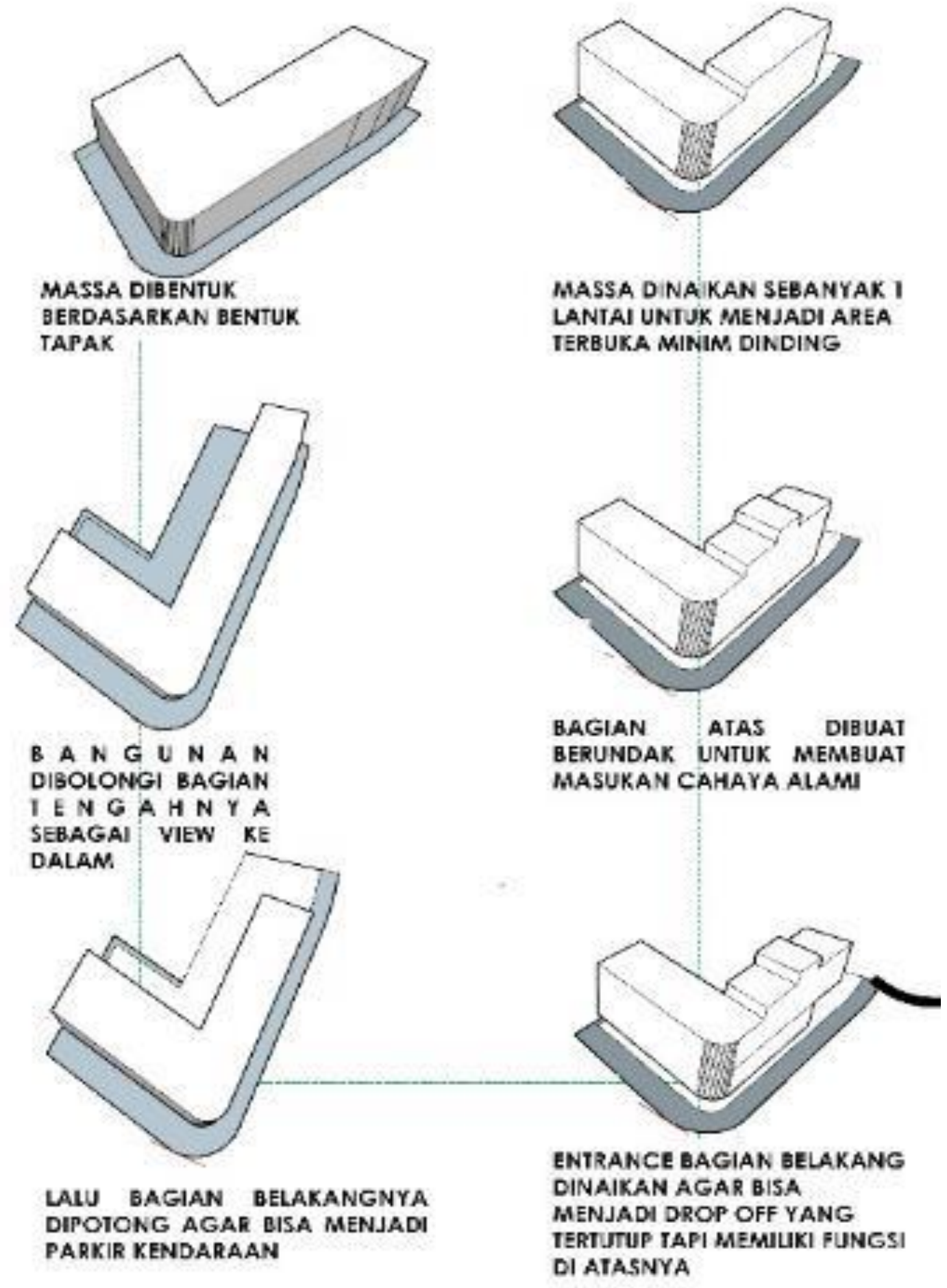

Gambar 12. Design Scheme

Sumber : Penulis, 2019 


\section{KESIMPULAN DAN SARAN}

\section{Kesimpulan:}

a. Suatu tempat menjadi third place karena adanya 8 kriteria third place

b. Solusi agar program third place dapat dilaksanakan adalah dengan adanya program yang bersahabat dengan publik dengan menerapkan teori-teori yang ada di buku pattern language.

c. Third place bisa beroperasi selama 24 jam dengan menggunakan teori solidarity economy. Dimana orang bisa menggunakan fasilitas tanpa memiliki dan memiliki bagian pengelola. Adapun demikian pengelola tidak selalu harus mengurus segala sesuatunya. Melainkan dapat mengambil pengurus seperti kebersihan dan reparasi dari tempat lainnya

\section{Saran:}

Sesuai dengan hasil evaluasi desain, penulis menyarankan program-program third place yang dilaksanakan untuk menjadi sebuah public space yang bisa dinikmati semua kalangan dan juga memenuhi kebutuhan pengunjung yang menjadi target.

\section{REFERENSI}

Mclaren, D. , Ageyman, J. (2015). Sharing Cities: A Case for Truly Smart and Sustainable Cities. Cambridge: The MIT Press.

Miller, E. (2010). Solidarity Economy. Australia

Oldenburg, R (1989). The Great Good Place: Cafes, Coffee Shops, Community Centers, Beauty Partors, General Stores, Bars, Hangouts, and How They Get You Through the Day. New York: Paragon House.

Tjahjono, G. (2000). Metode Perancangan Suatu Pengantar untuk Arsitek dan Perancang. Depok: Universitas Indonesia.

UNESCO. (2019) Sustainable Development Goals. Diakses Juli 20, 2019. Diakses dari https://www.un.org/sustainabledevelopment/sustainable-development-goals/

White, E. T. (1987). Concept Sourcebook. Bandung: Intermatra.

DUKCAPIL. (2018) Data kependudukan DKI Jakarta. Diakses Juli 20, 2019. Diakses dari http://kependudukancapil.jakarta.go.id/pages/?page=fullpage

Jakarta Satu. (2014). Peta Zonasi DKI Jakarta. Diakses Juli 20, 2019. Diakses dari https://jakartasatu.jakarta.go.id 
